\title{
Load Transfer Stiffness of Two-layer Roller Compacted Concrete for Pavements
}

\author{
Haneen Mohammed ${ }^{1 *}$, Nick Thom ${ }^{2}$, Andrew Dawson ${ }^{2}$ \\ 1. American University of Madaba, Jordan \\ 2. Nottingham Transportation Engineering Centre [NTEC], Department of Civil Engineering, University of \\ Nottingham, Nottingham NG7 2RD, UK, \\ E-mail: haneen.civil.2009@gmail.com (Corresponding Author); nicholas.thom@nottingham.ac.uk; \\ andrew.dawson@nottingham.ac.uk
}

Received: 6 August 2019; Accepted: 1 September 2019; Available online: 25 October 2019

\begin{abstract}
Roller compacted concrete (RCC) is a form of plain concrete pavement (JPCP). RCC is a zero-slump concrete consisting of well-graded aggregate, cement and water. RCC has many advantages over other pavement types, particularly cost and speed of construction. Recently, RCC has undergone many developments mostly directed towards improving quality, including smoothness and durability. RCC now has the potential to combine the performance of concrete with the low cost of asphalt installation. A two-layer system of RCC with different aggregate types and sizes was utilized in this study. This paper presents the determination of load transfer stiffness across induced joints in a two-layer RCC system based on a cyclic shear test. The test was carried out for three different upper layer placement cases with different crack widths and load magnitudes. From the test results, an approximate equation was formulated to predict joint deterioration. It is suggested that this equation provides a useful tool to assist in the design of two-layer RCC pavement and, potentially for other concrete pavement types. Keywords: RCC; Joints; Two-layer system; Load transfer stiffness; Cyclic shear test.
\end{abstract}

\section{Introduction}

Roller compacted concrete (RCC) is a mixture of dense-graded aggregates, cement and water. It is placed with a high compaction asphalt type paver and compacted to high density (> 95\% maximum dry density) by vibratory rollers to provide a high strength and durable pavement structure [1, 2].

The first widespread use of RCC was in the 1970's by the Canadian logging industry when the new land-based log sorting methods needed a strong, fast but economic paving system that could take very large loads [3]. Over the years, RCC has undergone several developments, most directed towards improving quality, including smoothness and durability. A major improvement in ride quality arrived with the use of asphalt pavers, and RCC now has the potential to combine the performance of concrete with the low cost of asphalt placement $[4,5]$.

Multiple lifts have been used for RCC pavements when the total thickness is more than about $250 \mathrm{~mm}$. This is to ensure adequate compaction of each lift and to develop sufficient bond at the interface between lifts so that the RCC can be considered monolithic. To achieve this, specifications recommend that the placement of the layers should generally be done within a time limit of 1 hour of each other in order to ensure good bond between layers [6]. The bottom layer serves as the main bending-resistant component of the composite slab, while the top lift is generally constructed with higher-quality constituent materials for improved surface characteristics such as noise and skid resistance [7].

RCC is a form of jointed plain concrete pavement (JPCP). An important role of the aggregate in concrete pavements is to provide load transfer across joints and cracks by means of aggregate interlock which in theory can eliminate the need for load transfer devices. Historically, to increase the economy of construction, RCC pavements have been allowed to crack naturally and this has proven to be very successful. However, to achieve a higher standard of road, controlled placement of joints is required.

Joints in RCC pavement are clearly critical areas and form weak points. RCC is similar to conventional concrete pavements in that it can have different types of joint such as construction joints, sawn (contraction) joints, and expansion joints which are full-width transverse joints placed at regular intervals in the pavement. Longitudinal and transverse construction joints are generally a practical necessity. Longitudinal and transverse joints, sawn through only part of the layer thickness, are normally used to control random cracking and to provide a mechanism to control the spacing of cracks $[8,9]$. 
Joints are typically sawn every 8-12 meters to reduce most of the random shrinkage cracking and to improve the appearance of the final RCC pavement [6]. This compares with the findings of Harrington et al. [8] who reported that natural cracks typically occur at 6.1 to $18.3 \mathrm{~m}$ intervals, depending on the properties of RCC and pavement thickness. Contraction joints can be constructed using early-entry sawing to a depth of 1/4 to 1/3 of the total layer thickness usually within two to three hours of paving. The first cracks will appear within 24 hours of placement because of shrinkage. Therefore, contraction joints are typically sawn at regular intervals along the length of the slab, usually within the first 24 hours, to control the location of the cracks by creating weakened planes. This avoids large separation between cracks and thus leads to reduced curling and warping stresses [10]. The Portland Cement Association (PCA) recommends that joints should be spaced no more than $6 \mathrm{~m}$ apart and, for slab thickness less than $200 \mathrm{~mm}$, joint spacing should be between 4.6-6 $\mathrm{m}$ [6, 8].

An important characteristic of concrete pavement joints in the design procedures is load transfer (or joint efficiency). Load transfer refers to the ability of a joint or crack to transfer load from one slab to an adjacent slab, thereby reducing the amount of load and therefore stress which must be borne by an individual slab. Joint efficiency is a measure of load transfer, being the portion of deflection due to a load on one slab that is transferred to an adjacent slab through the joint. Load transfer is improved by limiting the spacing between joints [11, 12] since thermally induced expansion and contraction will be less concentrated.

Natural load transfer occurs across cracks that form naturally after placing the concrete slab or that were induced by sawing or placing an insert to form the crack. Load transfer is a complex mechanism that can vary with concrete pavement thickness, joint spacing, temperature, moisture content, aggregate type and size, age, construction quality, magnitude and number of repetitions of load, and type of joint [11]. Ioannides and Korovesis [13] suggested that a pure shear load transfer mechanism is preferable to transmitting bending because the warping effect would induce further stress if bending movement is prevented.

Practically, for design, the concept of load transfer in a jointed concrete pavement is very important, as exemplified by the Corps of Engineers and Federal Aviation Administration (FAA) procedures for rigid pavements. These procedures assume that $25 \%$ of the load applied at the edge of a concrete pavement slab, which is the most critical loading position, is transferred through the joint to the adjacent unloaded slab. This therefore reduces the edge stress in the loaded slab by $25 \%$ from a maximum free edge condition thereby allowing for a reduced slab thickness. The $25 \%$ load transfer assumption in the Corps of Engineers and FAA design procedures is a simplifying assumption. If the load transfer assumption is not met, the life of the pavement may be significantly reduced from the design life expected [11].

Load transfer in RCC pavements is achieved solely through aggregate interlock, which relies on the shear force developed from the friction at the rough vertical interface of a concrete pavement joint (Pittman, 1994). PCA state that RCC crack efficiencies of $60 \%$ are expected with saw-cut joints and 60-90\% for naturally cracked joints [14]. However, Harrington et al. [8] report that the joint efficiency of RCC ranges between 22\% and $89 \%$ depending on the type of joint or crack test method and the temperature at the time of test.

The stiffness of a joint, as described by Hung [15] can be represented by two terms, a shear spring constant, $\mathrm{C}_{\mathrm{w}}$, which is defined as the shear force per unit length of joint divided by the difference in deflections between two slabs, and a moment spring constant, $\mathrm{C}_{\theta}$, described as the moment per unit length of joint divided by the difference in rotations between the two slabs. Ioannides and Korovesis [13] demonstrated a relationship between load transfer efficiency (LTE), which represents the ratio between the deflections on the unloaded side of the crack and the loaded side of the crack, and the shear spring constant used in the ILLISLAB95 program to transfer load in shear. Moreover, Thompson [16] analysed two slabs of cement bound material with one joint to design a base layer of a composite pavement, using a relationship between joint spring stiffness per unit area (obtained from a cyclic shear test in terms of load transfer stiffness (LTS) and joint spring stiffness per unit length in terms of aggregate interlock factor (AIF) (spring constant $C_{w}$ ) in order to find the critical stresses along the joint using Equation 1, where $\mathrm{D}$ is the depth of the slab.

$$
A I F=\operatorname{LTS} X D
$$

Moreover, Ellis et al. [17] reported a comparison between natural cracks and induced cracks in cement bound materials based on LTE data and they found, for their specific case, that in situ $\mathrm{C}_{\mathrm{w}}$ was in the range of $217 \pm 89$ MPa for natural cracks and $982 \pm 447 \mathrm{MPa}$ for induced cracks, reinforcing the benefits of crack control.

Thus, this paper aims to determine the load transfer stiffness (LTS) for a two-layer RCC system using a laboratory test, namely the cyclic shear test, as a function of the crack width, applied shear stress and second layer placement condition. It also aims to develop an equation that can predict the joint deterioration of RCC and other types of concrete pavement for use in pavement performance predication.

\section{Materials and methods}




\subsection{Materials selection}

Two types of mixture have been used in this study of two-layer systems, a lower layer with crushed Carboniferous limestone aggregate (ex: Tunstead quarry, Derbyshire) and maximum size $20 \mathrm{~mm}$ and an upper layer with crushed granite aggregate (ex Bardon Hill quarry, Leicestershire) and maximum size $10 \mathrm{~mm}$, since they are readily available in the UK. Both sources comprised angular particles. The choice of granite aggregate for the upper layer was due to its high skid resistance and abrasion resistance, while the limestone was chosen as a cheaper material with high strength for the lower layer. The gradations were chosen according to the UK's MCHW-800 document [18] and conforming to BS EN 14227-1[19]. They are shown in Figures 1 and 2. The cement type used in this research was Portland cement CEM I- 42.5/52.5N conforming to BS EN 197-1 [20].

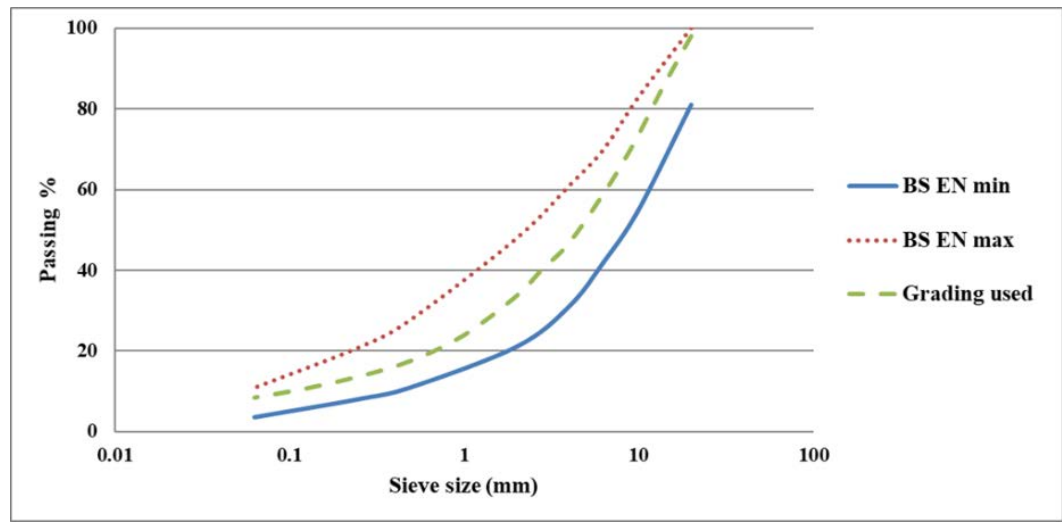

Figure 1. Gradation of $20 \mathrm{~mm}$ combined limestone aggregate

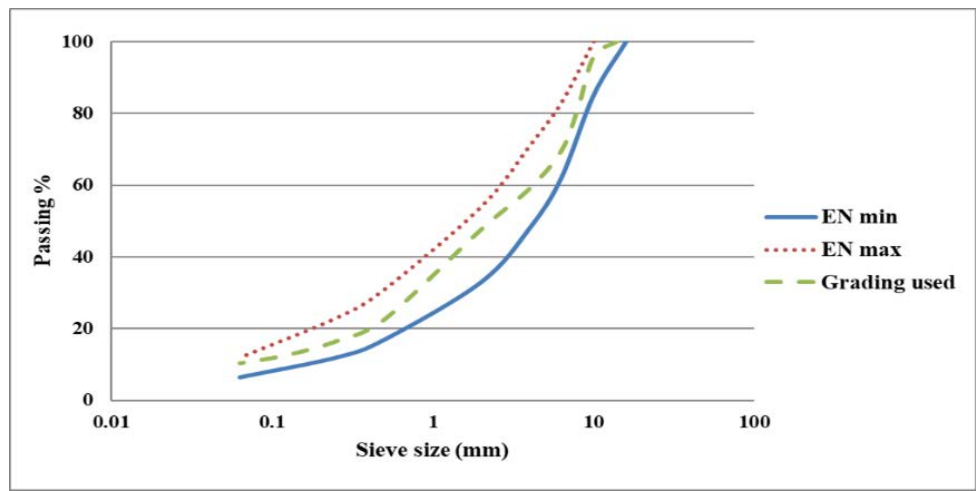

Figure 2. Gradation of $10 \mathrm{~mm}$ combined granite aggregate

\subsection{Mix design and specimen preparation}

The design of the two mixtures followed a geotechnical approach by finding a relationship between optimum moisture content and maximum dry density according to ASTM D 1557 [21], combined with a strength requirement. For this study $34 \mathrm{MPa}$ compressive strength was chosen. The proportions determined were $12 \%$ cement and $7 \%$ water. Regarding the mixing sequence, the dry materials (coarse aggregate, fine aggregate and cement) were mixed together in a concrete pan mixer for 1 minute, then the water was added and mixing continued for a further 2 minutes, giving a visually homogeneous mixture. Slab samples were prepared in a square steel mould with dimensions $305 \mathrm{~mm} \times 305 \mathrm{~mm} \times 100 \mathrm{~mm}$ according to EN 12697-33 [22] and compacted by a laboratory roller compactor in order to simulate field conditions as closely as possible. A piece of paper was placed between the concrete and the roller to prevent adhesion. For two-layer RCC samples, three cases were trialled, simulating different levels of delay that may happen during construction. The three cases are listed below:

1) Case 1: the upper and lower layers were placed and compacted within one hour of each other.

2) Case 2: the upper layer was constructed three hours after the lower layer.

3) Case 3: the upper layer was constructed 24 hours after the lower layer.

The bond properties have been studied in detail by Mohammed [23] who investigated, amongst other aspects, whether bond could be improved by specific preparation processes applied to the top of the lower layer before the upper layer is placed. However, since no great benefit was observed by use of special treatment techniques, none were applied in the current study.

All samples were removed from the mould 24 hours after constructing the upper layer and left in water for 28 days at $20^{\circ} \mathrm{C}$ before testing. Figure 3 shows the preparation phases for RCC samples. Compressive strength and 
indirect tensile stiffness were tested for each case without cracks, where loading was applied perpendicular to the interface between layers in compressive strength tests and in the direction of the interface in indirect tensile stiffness tests. The results showed high strength and stiffness reaching $34 \mathrm{MPa}$ and $32 \mathrm{GPa}$ respectively for each layer when the bond strength was achieved properly.

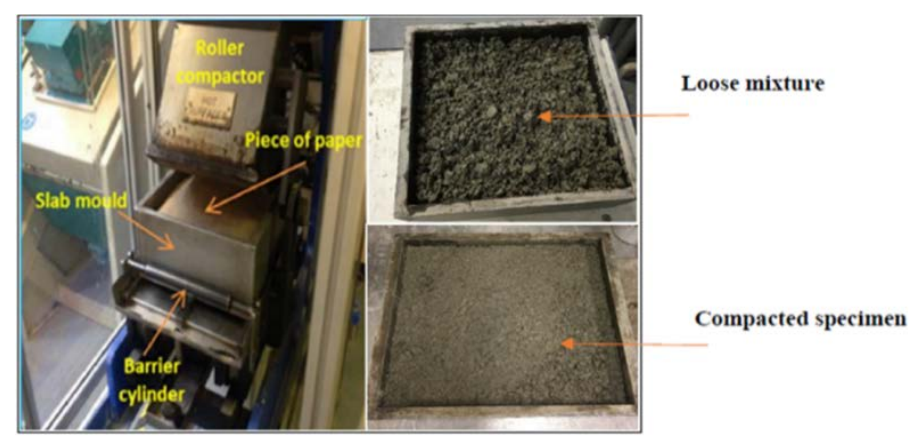

Figure 3. Preparation of RCC samples by roller compactor

\subsection{Cyclic shear test}

This test was carried out on two-layer RCC prism samples with dimensions of $60 \times 60 \times 305$ mm to investigate crack properties, where any improvement in the shear stiffness of a transverse crack would improve the load transfer characteristics of a pavement. Crack properties of two-layer RCC pavements were investigated at three approximate crack widths, $0.2 \mathrm{~mm}, 0.5 \mathrm{~mm}$ and $1 \mathrm{~mm}$. To induce the cracks, two notches were first sawn around the perimeter of each prism to a depth of approximately $5 \mathrm{~mm}$ using a steel saw as shown in Figure 4 . Hairline cracks were then induced in each prism, vertically, using a small hammer.

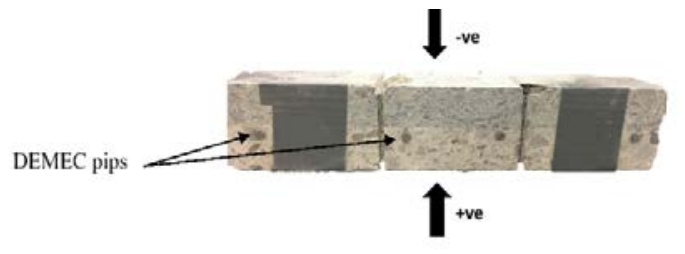

Figure 4. Test specimen before testing

The average cross-sectional area at each notch was calculated by measuring the width and thickness of the beam with a Vernier gauge. The presence of the crack was confirmed by visual inspection of the beam and the crack width was measuring using DEMEC pips mounted on the faces of the specimen. To obtain cracks of the desired width $(0.2,0.5$ and $1 \mathrm{~mm})$, a digital Vernier gauge was used to measure the crack widths inside the machine before starting the test, then corrections were made at intervals during the test.

The specimens were then subjected to shear stress ranges across the cracks of $\pm 195 \mathrm{kPa}, \pm 250 \mathrm{kPa}, \pm 278 \mathrm{kPa}$, chosen based on previous test experience. A positive stress represents load on the central test element in an upward direction and a negative load downward. 1000 cycles were applied at each load level. Machine control and data acquisition were achieved using MOOG software and a servo hydraulic load frame machine with $100 \mathrm{kN}$ capacity as shown in Figure 5. The end parts of the specimen were fully restrained vertically and horizontally while the central part, between the cracks, moved up and down at an amplitude depending on the crack condition.

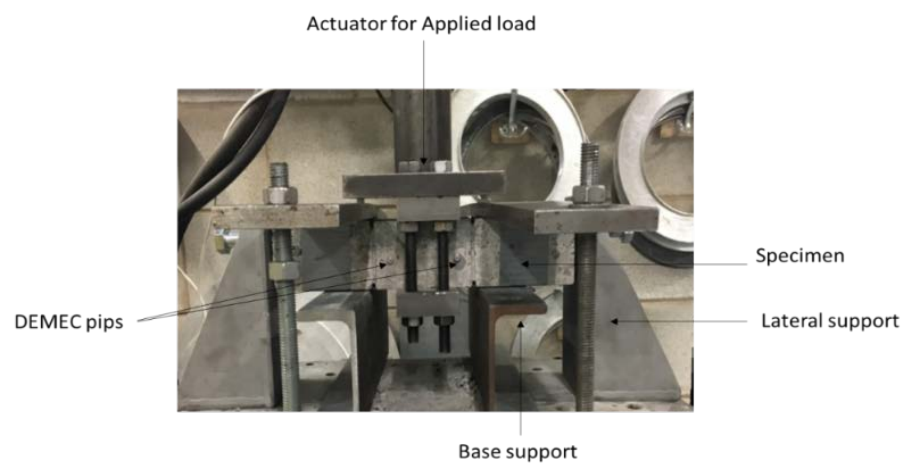

Figure 5. Cyclic shear test arrangement 


\section{Results and discussion}

\subsection{Results of cyclic shear test}

The results are discussed in terms of the effect of different crack widths, shear stresses and placement conditions. At each load level, start and end measurements evaluated the average shear stiffness over ten cycles for an average of two specimens in each condition. Typically, the difference between the two specimens in each pair was less than $10 \%$. Figure 6 shows the effect of different crack widths $(0.2 \mathrm{~mm}, 0.5 \mathrm{~mm}$ and $1 \mathrm{~mm})$ at $195 \mathrm{kPa}$ for the first placement case (upper layer placed within one hour of the lower layer) at the beginning and end of the 1000 cycles. The relation between applied load and shear slip (where shear slip is defined as the vertical distance moved under the applied load) indicated as expected, that the shear slip increases with increasing crack width, and also with increased deterioration of the joint.

At low crack widths, the load-shear slip response was often approximately linear, while at higher crack widths, the relationship between load and shear slip was distinctly non-linear. It appears that when the crack width is low, the whole crack face contributes to shear resistance. This results in a linear load-shear slip relationship and low crack deterioration. However, the non-linear relation at higher crack widths might logically be explained by the finer aggregate no longer contributing to aggregate interlock, with the load being carried by the larger aggregate only. Some deterioration between beginning and end of the test is also apparent.

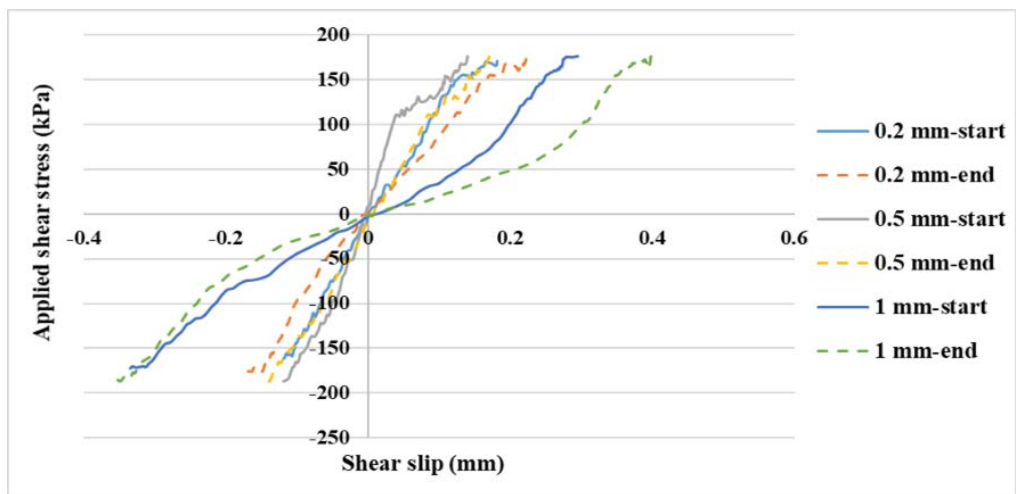

Figure 6. Relationship between applied load and shear slip for Case 1 at $195 \mathrm{kPa}$ for different crack widths

Figure 7 presents the relationship between the applied shear stress and shear slip for the second case (upper layer constructed 3 hours after lower layer) at $0.2 \mathrm{~mm}$ crack width at different applied stress levels. This figure shows the effect of shear stress on the deterioration of a narrow crack. It can be observed that increasing the shear stress from $195 \mathrm{kPa}$ to $278 \mathrm{kPa}$ has a relatively small effect on crack shear stiffness. This can be attributed to good interlock achieved across the narrow crack, together with the relatively good bond strength between the two layers.

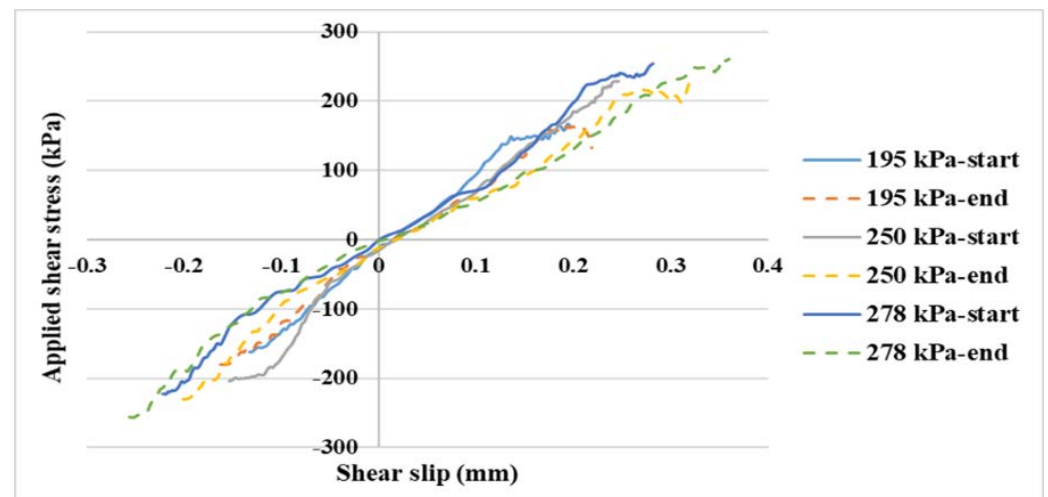

Figure 7. Relationship between applied shear stress and shear slip for Case 2 with $0.2 \mathrm{~mm}$ crack at different shear stresses

Furthermore, Figure 8 shows the relationship between applied shear stress and shear slip for different placement conditions and $0.5 \mathrm{~mm}$ crack width, and it is clear that poorer bond quality between the layers led to dramatically poorer joint efficiency and a greater level of deterioration during the test. The results for Case 2 (the upper layer placed three hours after the lower layer) were much worse than for Case 1 (upper layer placed within one hour), 
while Case 3 (the upper layer placed 24 hours after the lower layer) was significantly worse again. Delayed placement also resulted in a more non-linear behaviour as well as greater deterioration.

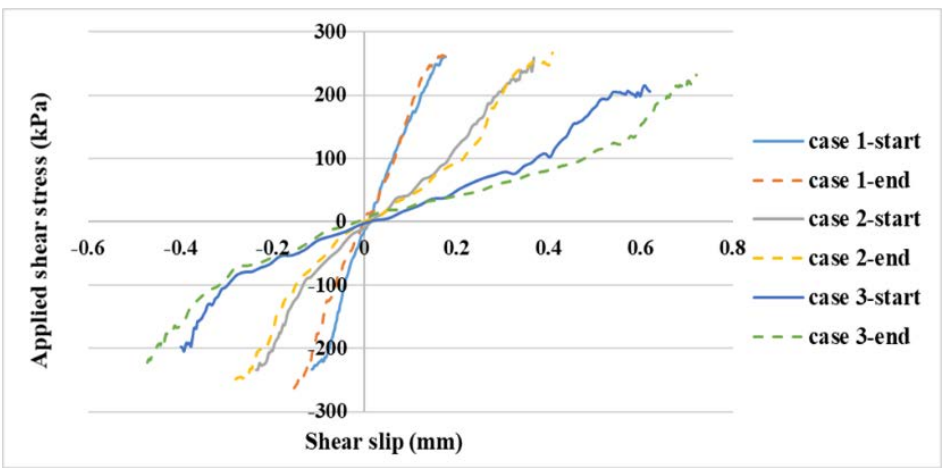

Figure 8. Relationship between applied shear stress and shear slip at $0.5 \mathrm{~mm}$ crack width and $278 \mathrm{kPa}$ shear stress

\subsection{Results of load transfer stiffness}

From the load-shear slip data, load transfer stiffness (LTS) was calculated as the applied shear stress per unit shear slip. For each test, the applied load and the cross-sectional area of both crack faces remained constant. Therefore, any increase in the shear slip during the tests implied a reduction in the load transfer stiffness.

Figure 9 shows load transfer stiffness for all three construction cases, crack widths and applied stresses, at three stages (in most cases) during each set of 1000 load applications. It can be seen that the deterioration of the cracks in this two-layer RCC system increased with increasing number of cycles, increasing shear stress and increasing crack width, as well as being greatly affected by placement conditions.

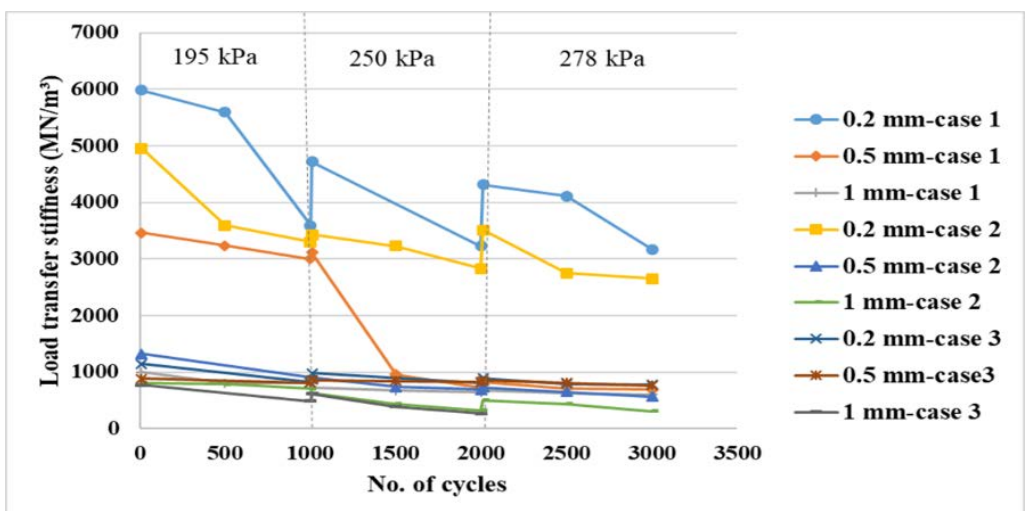

Figure 9. Relationship between load transfer stiffness and number of cycles for Case 1, Case 2 and Case 3 at different crack widths

\subsection{Load transfer stiffness equation}

As the cyclic shear test results combined four effects on load transfer stiffness, namely crack width, number of cycles, applied stress and placement conditions, a non-linear analysis was used to derive an approximate mathematical equation for the case of a good bond that could predict joint deterioration for this two-layer RCC pavement, which could then be used in pavement design.

The equation was determined based on non-linear relationships between test variables, with 26 data points representing the start and end points of each cyclic shear test. A simple Matlab code was created to find the constants in the equation by error minimisation [24]. The equation is shown below:

$$
L T S=\frac{0.022\left(\frac{\tau}{M O R}\right)^{-2.2}}{W\left(29+N^{0.4}\right)}
$$

where LTS is load transfer stiffness $\left(\mathrm{MN} / \mathrm{m}^{3}\right), \tau$ is the shear stress $(\mathrm{kPa}), \mathrm{MOR}$ is modulus of rupture $(\mathrm{kPa})$ from 3-point bending tests, $\mathrm{W}$ is the crack width $(\mathrm{m})$ and $\mathrm{N}$ is the number of load cycles. This equation is approximately valid over the range for which data was obtained as shown in Figure 10, which shows the correlation between the computed load transfer stiffness (LTS) and measured LTS from cyclic shear tests. The equation has also been constrained to give long-term LTS values in the range typically found across concrete joints in practice, i.e. $10^{2}$ $10^{4} \mathrm{MN} / \mathrm{m}^{3}$ [25] ensuring the potential usefulness of this equation to predict joint deterioration under repeated load. 


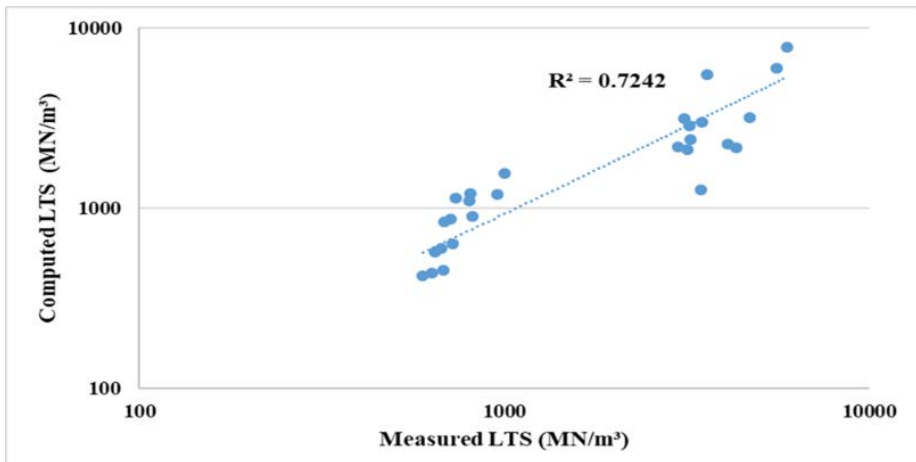

Figure 10. Relationship between computed load transfer stiffness and measured load transfer stiffness

The computed joint deterioration for different crack widths based on Equation (2) can be seen in Figure 11. It can be observed that increasing crack width significantly affects the stiffness of the joint after a large number of repeated loads. However, increasing the shear stress has a more minor effect.

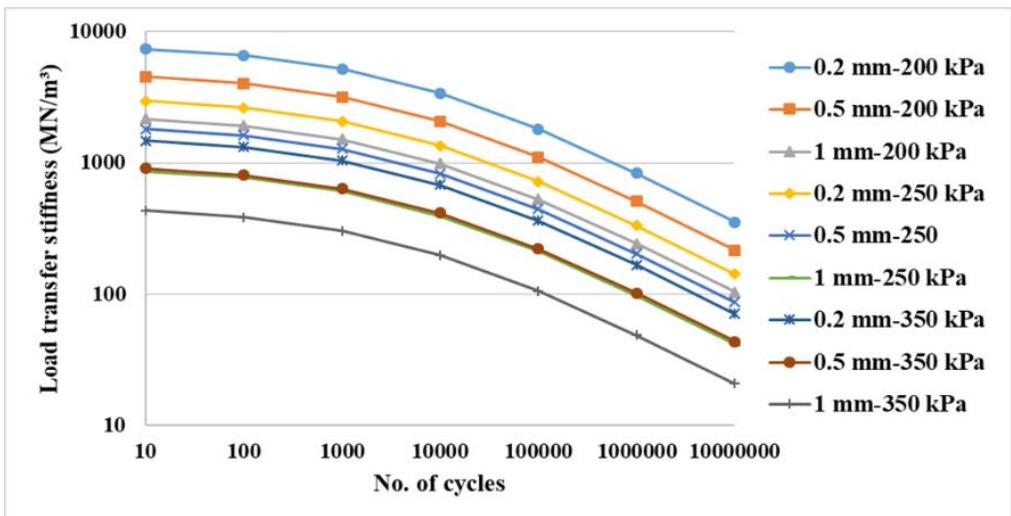

Figure 11. Relationship between load transfer stiffness and number of cycles for different crack widths at $200 \mathrm{kPa}$, $250 \mathrm{kPa}$ and $350 \mathrm{kPa}$ shear stress

\section{Conclusions}

RCC has proven to be a reliable, economical, durable material for pavements. The effectiveness of joints in two-layer RCC depends on their efficiency in transferring the load and this is given by the load transfer stiffness of joints. Cyclic shear tests were conducted to find the joint stiffness of a two-layer RCC system. The results showed that joint stiffness depends significantly on crack width, on the number of load cycles applied, on the applied shear stress and on the quality of bond between the upper and lower concrete layers. It can be concluded from the test results that the crack deteriorates relatively quickly when the width is high and when the placement conditions weaken the bond between layers. Based on the testing carried out, an equation for joint load transfer stiffness has been designed and is able to predict the deterioration of a joint in single-layer or well-bonded twolayer RCC under a large number of cycles as a function of material properties. It is believed that this equation provides a useful tool to assist in the design of two-layer RCC pavement and, potentially, for other concrete pavement types also.

\section{Acknowledgements}

The support from the Higher Committee of Education Development in Iraq (HCED) by providing a scholarship for this research is gratefully acknowledged. The author also acknowledges the support of the technical staff of the Nottingham Transportation Engineering Centre (NTEC) at the University of Nottingham.

\section{References}

[1] Donegan JP. Roller compacted concrete. ICE Manual of Highway Design and Management. 2011 ed. Institution of Civil Engineers.

[2] Bauchkar SD, Chore HS. Roller compacted concrete: A litrature review. IOSR Journal of Mechanical and Civil Engineering (IOSR-JMCE). 2012: 28-32. 
[3] ERMCO-Guide. Ermco guide to roller compacted concrete for pavements.ERMCO, European Ready Mixed Concrete Organization;2013.

[4] Piggott RW. Roller-compacted concrete pavements: A study of long term performance. Portland Cement Association; 1999.

[5] Delatte N, Amer N, Storey C. Improved management of RCC pavement technology. UTCA Report, 1231, 54. 2003.

[6] ACI-325.10R. Report on roller-compacted concrete pavements. Technical report. ACI Committee 325. 2001.

[7] Rao S, Darter M, Tompkins D, Vancura M, Khazanovich L, Signore J, Coleri E, Wu R, Harvey J, et al. Composite pavement systems volume 2 pcc/pcc composite pavements. Technical report. Sharp 2 report, Report S2-R21-RR-3. 2013.

[8] Harrington D, Abdo F, Adaska W, Hazaree C. Guide for roller-compacted concrete pavements. National concrete pavement technology centre Iowa State University's Institute for Transportation Portland Cement Association; 2010.

[9] White TD. Mix Design, Thickness design, and construction of roller-compacted concrete pavement. Transportation Research Record. 1986;1062:1-6.

[10] Pittman DW, Ragan SA. Drying shrinkage of roller-compacted concrete for pavement applications. Materials Journal. 1998;95(1):19-26.

[11] Pittman DW. Development of a design procedure for roller-compacted concrete (RCC) pavements. [PhD thesis]. U.S. Army Corps of Engineers and Waterways Experiment Station. 1994.

[12] Arnold SJ. Load transfer across cracks and joints in concrete slabs on grade. [PhD thesis]. Loughborough University. 2004.

[13] Ioannides AM, Korovesis GT. Aggregate interlock: a pure-shear load transfer mechanism. Transportation Research Record. 1990(1286).

[14] Griffiths G, Thom N. Concrete pavement design guidance notes. CRC Press; 2007.

[15] Huang YH. Pavement analysis and design. Pearson prentice hall, Pearson education, Inc.; 2004.

[16] Thompson I. Use of steel fibres to reinforce cement bound roadbase. [PhD thesis]. University of Nottingham. 2001.

[17] Ellis SJ, Megan MA, Wilde LA. Construction of full-scale trials to evaluate the performance of induced cracked CBM roadbases. Transport Research Laboratory, Crowthome. LR 289. 1997.

[18] MCHW-800. Manual of contract documents for highway works, volume 1 specification for highway works. 2009.

[19] BS EN14227-1. Hydraulically bound mixtures - specifications - part 1: cement bound granular mixtures. European Standard. 2013.

[20] BS EN 197-1. Cement, composition, specifications and conformity criteria for common cements. London, England: British Standard Institution (BSI). 2011.

[21] ASTM-D1557. Laboratory compaction characteristics of soil using modified effort (56,000 Ft-Lbf/Ft3 (2,700 Kn-M/M3)). Annual Book of ASTM Standards Vol 04.08. 2000.

[22] EN12697-33. Bituminous mixtures - test methods for hot mix asphalt part 33: specimen prepared by roller compactor. European Standard. 2013.

[23] Mohammed HA. Assessing the bond strength of two layer roller compacted concrete (RCC) for pavements. In: World Conference on Pavement and Asset Management, WCPAM; 2017.

[24] Mohammed HA. Design and evaluation of two-layer roller compacted concrete. [PhD]. University of Nottingham. 2018.

[25] Thom NH. Principles of pavement engineering. ICE Publishing, London; 2018.

(C) 2019 by the author(s). This work is licensed under a Creative Commons Attribution 4.0 International License (http://creativecommons.org/licenses/by/4.0/). Authors retain copyright of their work, with first publication rights granted to Tech Reviews Ltd. 